\title{
Planning and Design
}

Search

Current issue Forthcoming

All volumes

EPB homepage

EP homepage

Pion homepage

Advance online publication

doi:10.1068/b120029p

Cite as:

Salvati L, Carlucci M, 2015, "Land-use structure, urban growth, and periurban landscape: a multivariate classification of the European cities" Environment and Planning B: Planning and Design advance online publication, doi:10.1068/b120029p

\section{Land-use structure, urban growth, and periurban landscape: a multivariate classification of the European cities}

\section{Luca Salvati, Margherita Carlucci}

Abstract. Assessment of urbanization and suburbanization patterns and processes in the European Union is becoming increasingly urgent for the formulation of common territorial policies. We hypothesize that the intrinsic characteristics of landscape at the city scale reflect both the local socioeconomic context and the regional trends towards urbanization, possibly representing the contrasting attitude towards suburbanization found in European countries. Using comprehensive information provided by Urban Atlas maps, we propose an exploratory multivariate analysis of eighty-five variables describing land-use composition, landscape structure, and urban form in 283 cities with the aim being to classify the urbanization patterns observed in five European macroregions. Landscape metrics seem to be more powerful in discriminating cities among regions than indicators of land-use composition. The most relevant metrics discriminating among cities are (i) those describing fragmentation processes along the urban gradient and (ii) those evaluating form and patchiness of discontinuous settlements. Landscape and class average patch size and edge density correctly classified cities in more than $80 \%$ of cases. In particular, cities in Southern, Eastern, and Northern Europe were identified as three homogeneous groups as far as landscape structure is concerned, confirming the converging urbanization trends in the Mediterranean countries and the peculiar morphological characteristics of post-socialist urban areas. Keywords: urban sprawl, socioeconomic context, Urban Atlas (UA), multivariate analysis, Europe

هull-text PDF ${ }_{\text {size: } 689 \mathrm{~kb}}$ 